\title{
A NEW SIMPLE DEVICE FOR DELIVERING CPPB TO INFANTS (A PRELIMINARY REPORT)
}

\author{
Edward Carden, M.A., M.B., B.ChIR., F.R.C.P.(C),
} Kenneth Levin, M.D., and R. Bruce Steinbach, A.R.I.T.

DURING THE LAST FEW YEARS the treatment of idiopathic respiratory distress syndrome in infants has undergone many changes and has markedly improved the survival of neonates stricken with this disease. One of the more recent changes in the treatment of this syndrome is the use of continuous positive pressure breathing $(\mathrm{CPPB})^{*}$. It is apparent, however, that while the conventional CPPB apparatus $^{1}$ (Figure 1) works extremely well it is rather large, bulky, and compli-

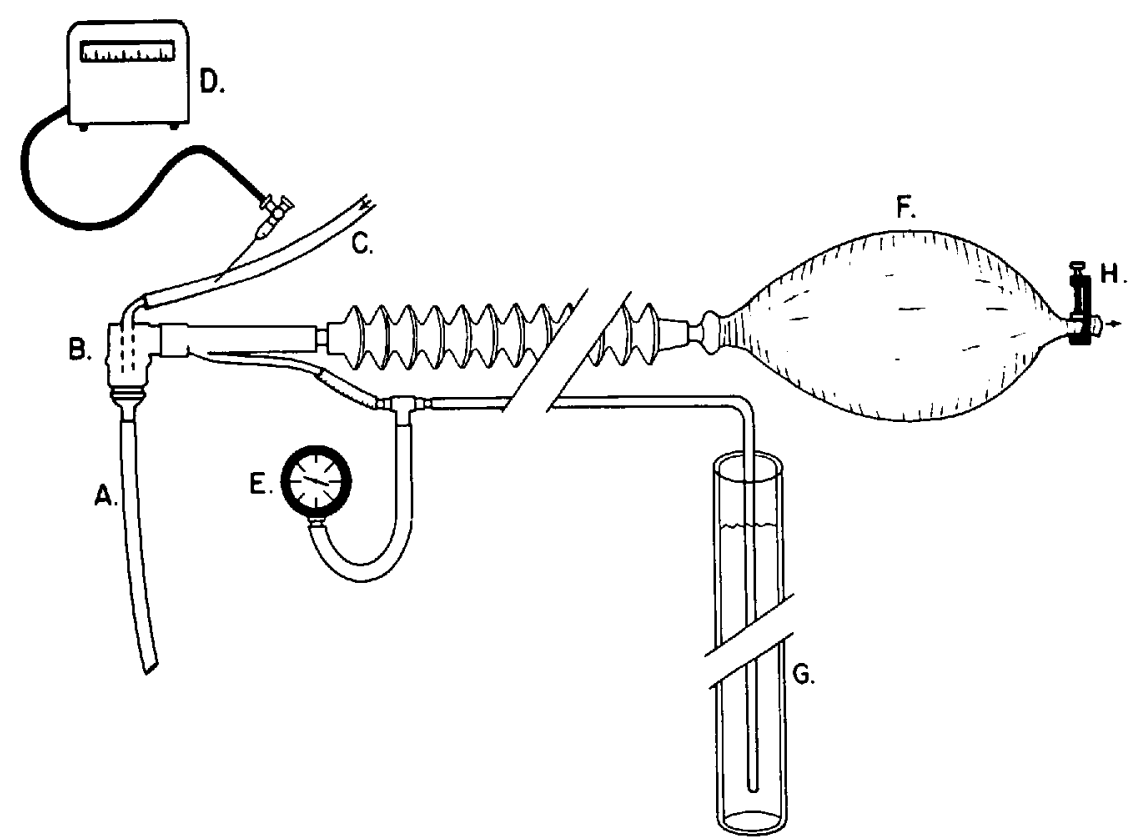

Figure 1. The conventional CPPB apparatus showing: A. Tracheal tube, B. Norman elbow, C. Fresh gas flow, D. Oxygen analyzer, E. Pressure gauge, F. Reservoir bag, G. Water safety valve, H. Clamp.

From the Department of Anesthesiology, University of North Carolina School of Medicine, Chapel Hill, North Carolina 27514, U.S.A.

"The term "constant positive airway pressure" (CPAP) is being eliminated and replaced by "constant positive pressure breathing" (CPPB). This denotes spontaneous breathing with endexpiratory pressure. Controlled ventilation with end-expiratory pressure will be known as "intermittent positive pressure ventilation with positive and expiratory pressure" (IPPV with PEEP). 4

Canad. Anaesth. Soc. J., vol. 21, no. 1, January 1974 


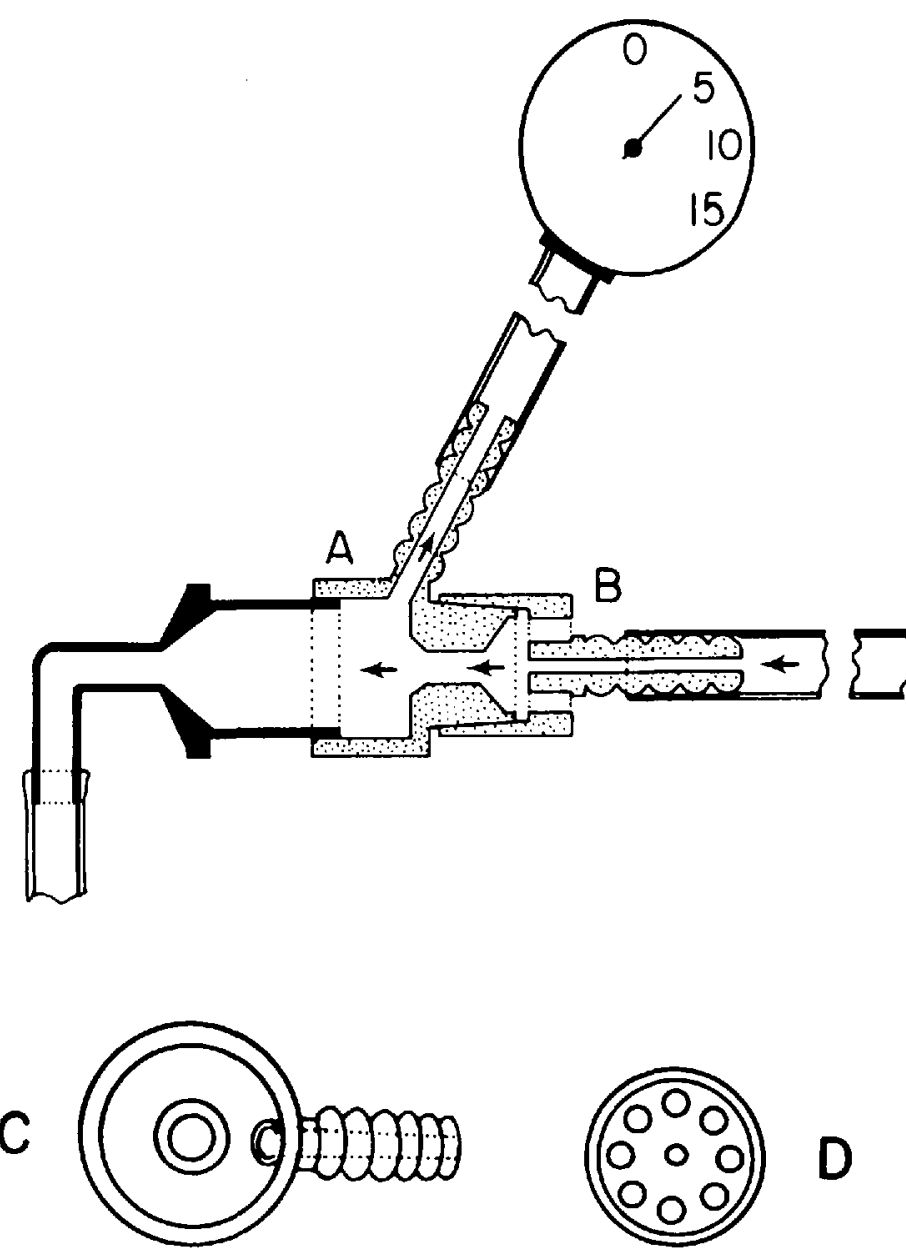

Ficure 2. Venturi CPPB apparatus showing part A connected to part B by a tapered connector. $C$ and $D$ are end-on views of parts $A$ and $B$.

cated for use with premature infants. A simpler device for the delivery of CPPB is described in this communication.

\section{METHOD}

A Venturi tube which creates positive pressure in the infant airway is utilized. This lightweight device is made of plexiglass, weighs only one-half ounce and consists of two parts (Figure 2). Part A consists of a Venturi tube with its connection to a pressure gauge terminating in a $15 \mathrm{~mm}$ female adapter for connection to a tracheal tube. Part B consists of a jet ( 0.050 inch) with its connection to fresh gas flow and eight radially arranged holes for the escape of excess and exhaled gases. The holes are approximately $0.080 \mathrm{inch}$, and so large enough not to be blocked by water. The two are joined together by a $12 \mathrm{~mm} / 2$ degree tapered connector. The Venturi tube is large enough in bore ( 0.2 inch) that 

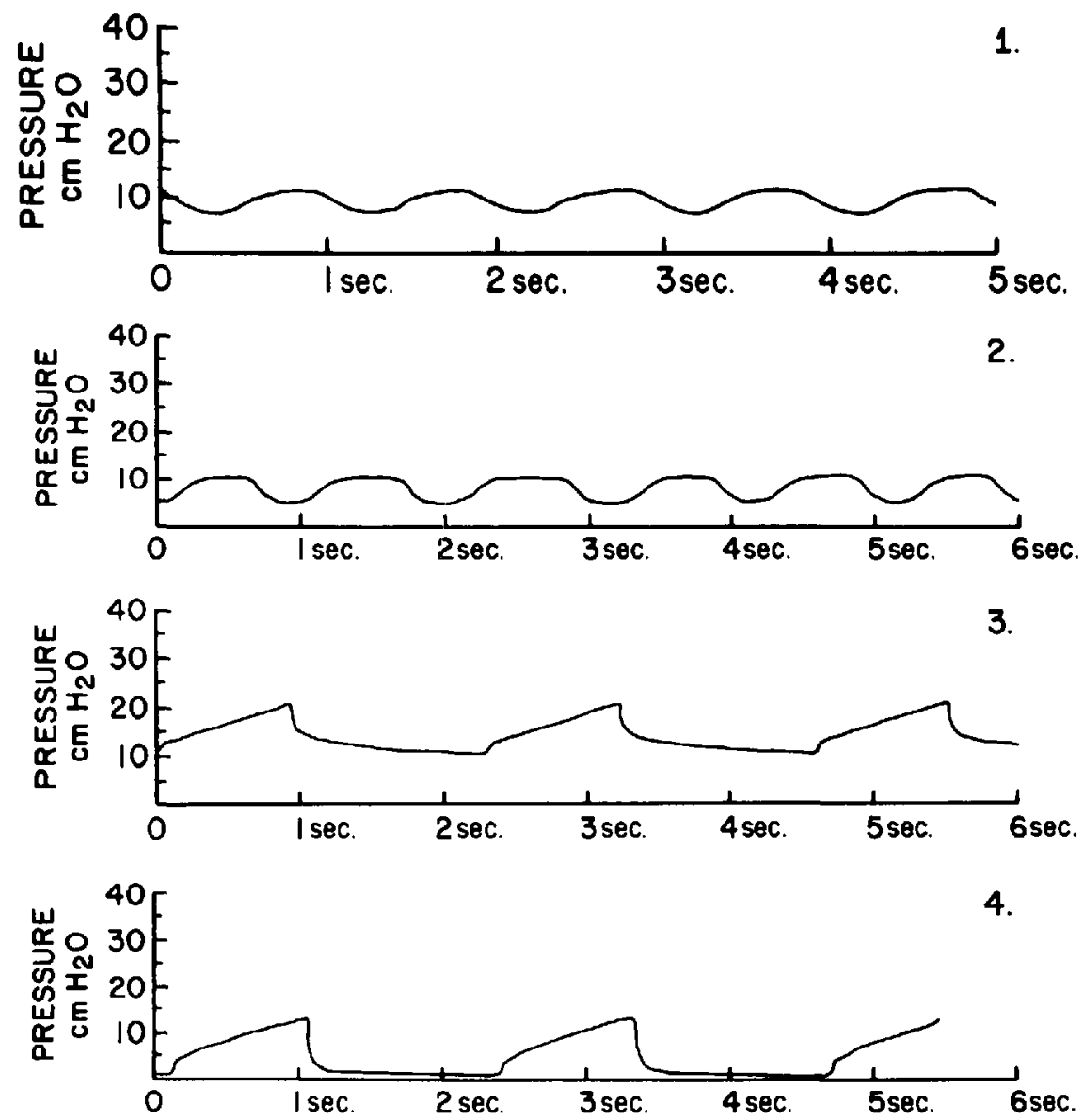

Figure 3. Time/pressure curves obtained from the airway of a nine-month-old child under anaesthesia. 1. Using a conventional CPPB apparatus set at $10 \mathrm{~cm} \mathrm{H}_{2} \mathrm{O}$ end-expiratory pressure. 2. Using the Venturi CPPB device set to deliver $10 \mathrm{~cm} \mathrm{H} \mathrm{H}_{2} \mathrm{O}$ end-expiratory pressure. 3. Using the Venturi CPPB device delivering $10 \mathrm{~cm}$ end-expiratory pressure with an "artificial thumb" type ventilator. 4. Using conventional T-piece with "artificial thumb" type ventilator.

resistance to gas flow is minimal. Likewise it is small enough that when gas flows of $5 \mathrm{~L} / \mathrm{min}$ are aimed into the Venturi tube in a direction opposite to the expiration of the child, pressures in the region of $5 \mathrm{~cm} / \mathrm{H}_{2} \mathrm{O}$ are created in the infant's airway. When flow is increased to $8 \mathrm{~L} / \mathrm{min}$, pressures in the order of $10 \mathrm{~cm} / \mathrm{H}_{2} \mathrm{O}$ are created. As the flow of gas is increased, the amount of end expiratory pressure created is also increased (Figure 3 ).

\section{Discussion}

The amount of dead space in this system is judged to be less than $2 \mathrm{ml}$, which would contribute minimally to retention of $\mathrm{CO}_{2}$, and its light weight allows for easy application to the infant. In practice we use a short reservoir tube of $15 \mathrm{ml}$ capacity attached to this unit to prevent entrainment of room air. With this modi- 
TABLE I

The Table Demonstrates the Effects of both the Conventional and Venturi CPPB Devices on a Newborn Child Suffering from Respikatory Distress Syndrome

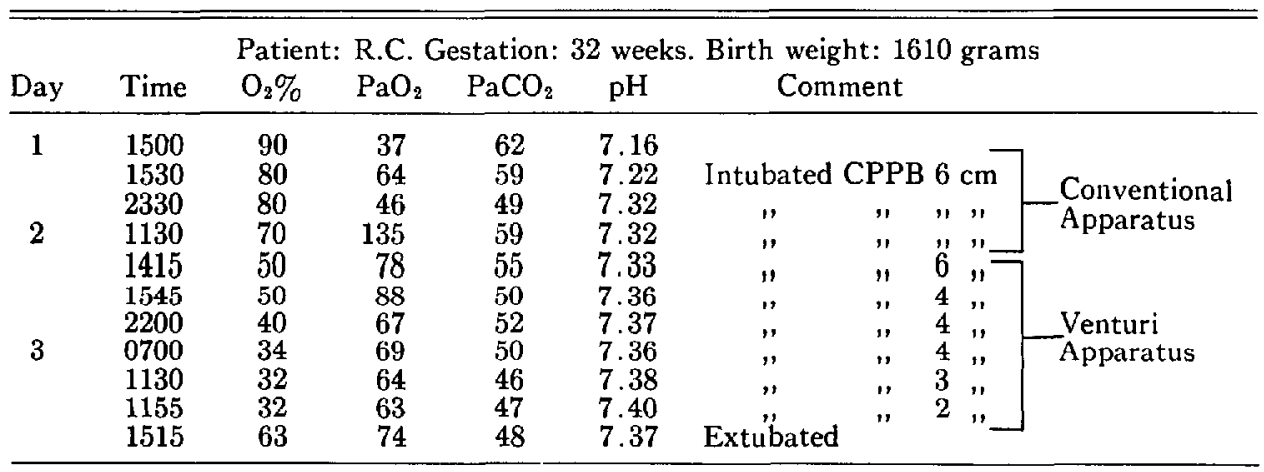

fication, the total weight of the unit plus reservoir tube is one ounce. By attaching a long reservoir tube to this unit and attaching the reservoir tube to a ventilator of the "artificial thumb" type (Amsterdam, ${ }^{2}$ Sheffield ${ }^{3}$ ) positive pressure ventilation with end expiratory pressure can be provided. The Venturi has also been used during anaesthesia when positive end expiratory pressures were needed, by substituting this device for the T-piece on a conventional T-piece circuit and adjusting the fresh gas flow to deliver the required amount of end-expiratory pressure. Preliminary studies indicate that the device improves oxygenation in infants stricken with respiratory distress syndrome as effectively as the Gregory unit (Table I). Further evaluation of this device is now being conducted in the paediatric intensive care units of four major centers.

\section{Conclusion}

An extremely simple device has been described with which constant positive pressure breathing can be delivered to infants. This device can be modified to create positive pressure ventilation with positive end-expiratory pressure. It has applications both in intensive care units and in the operating room.

\section{REFERENCES}

1. Gregory, G.A., Kitterman, J.A., Phibes, R.H., Tooley, W.H., \& Hamiton, W.K. Treatment of the idiopathic respiratory distress syndrome with continuous positive airway pressure. New Eng. J. Med. 284: 1333-1340 (1971).

2. KeUsKamp, D.H.G. Automatic ventilation in paediatric anaesthesia using a modified Ayre's T-piece with negative pressure during the expiratory phase. Anaesthesia 18: 46 (1963).

3. Mushin, W.W., Rendell-Bakeh, L., Thompson, P.W., \& Mapleson, W.W. The "E.G.C. paediatric" ventilator, automatic ventilation of the lungs. Second edition. Edited by Blackwell Scientific Publications. Oxford and Edinburgh, 1969, pp. 512-514.

4. Gregory, G.A. Continuous PPB therapy for neonatal respiratory distress. Hospital Practice, August, 1972. 